\title{
Commentary
}

\section{The Role of Mast Cells in Bacterial Enteritis}

\author{
Melanie A. Sherman \\ From the Department of Pathology and Laboratory Medicine, \\ Emory University School of Medicine, Atlanta, Georgia
}

Considering that the intestinal lumen is home to greater than 400 commensal bacterial species, it is curious that the mucosal immune system can detect the presence of pathogens among benign flora. The rapid and potent response of the innate immune cells ensures that virulent organisms are contained to the intestine, although this reaction can also damage surrounding tissue if not kept in balance. The work by Feng et $\mathrm{al}^{1}$ in this issue of The American Journal of Pathology demonstrates that mast cells are involved in the inflammatory reaction to intestinal pathogens and that mast cell products released during degranulation may be the cause of intestinal damage due to infection.

Several innate immune cell types reside in the intestinal lamina propria, including mast cells, dendritic cells, and macrophages. Within the intestine, mast cells are found in the mucosal and submucosal layer and can release a variety of bioactive proteins that can directly affect ion secretion (leading to diarrhea) and epithelial barrier function (leading to bacterial translocation). Although it is well documented that mast cell activation contributes to secretory diarrhea and colitis, it is still unclear how mast cells are triggered by microbial products to cause pathology. The observations presented here by Feng et $\mathrm{al}^{1}$ demonstrate that Toll-like receptor (TLR)2 on mast cells is responsible for diarrhea caused by Staphylococcus aureus. This work is a culmination of past studies demonstrating that mast cell products affect intestinal physiology and that mast cells are an important part of the innate immune response to bacterial infection.

\section{What Is the Evidence That Mast Cells Influence Gastrointestinal Function?}

Mast cells were first observed to be increased in tissue biopsies from patients with inflammatory bowel disease. ${ }^{2}$ The increased number of mast cells also associates with evidence of mast cell degranulation and the extent of degranulation correlates with the degree of inflammation. It is worth noting that mast cells appear to be grouped specifically along the line of demarcation separating healthy tissue from inflamed tissue in ulcerative colitis patients ${ }^{3}$ and also with strictures in Crohn's disease. ${ }^{4} \mathrm{~A}$ second observation is the reactivity of pANCA with mast cells. The generation of pANCA antibodies is found in 68 to $80 \%$ of ulcerative colitis patients and is thought to be either a preclinical marker for disease or a susceptibility factor. ${ }^{5}$ Importantly, pANCA reacts to a cytoplasmic factor found in mucosal mast cells located in the colon. ${ }^{6}$ These observations suggest that mast cells are associated with intestinal inflammation and can be a target for autoimmune antibody development.

However, conclusive evidence comes from studies using mast cell-deficient animals. Ws/Ws rats, which have a small deletion in the c-kit gene and therefore do not develop mast cells, are resistant to experimentally induced colitis with dextran sodium sulfate. ${ }^{7}$ Mast celldeficient mice are resistant to enteritis caused by Clostridium difficile toxin, ${ }^{8}$ and mice that have been deleted of mast cells with c-kit antibody are resistant to diarrhea caused by oral allergens. ${ }^{9}$ In this issue of the AJP, Feng et $\mathrm{al}^{1}$ demonstrate that mast cell-deficient mice are resistant to peptidoglycan-induced diarrhea and that the mast cell stabilizer ketotifen can prevent gastrointestinal pathology caused by $S$. aureus. Reconstitution of the mast cell-deficient mice with mast cells recovers the inflammatory response. Thus, these experiments suggest that mast cells or their products contribute to intestinal inflammation and therefore are possible therapeutic targets for patients with acute or chronic diarrhea.

\section{How Do Mast Cells Cause Inflammation?}

Mast cells are unique in that they store preformed inflammatory mediators in their granules, poised for immediate release on activation. Like other immune cells, mast cells can also provide sustained release of these products as a result of de novo synthesis. Granules can also be re-

Accepted for publication May 25, 2007.

This commentary relates to Feng et al, Am J Pathol 2007, 171:537-547, published in this issue.

Address reprint requests to Melanie A. Sherman, Department of Pathology and Laboratory Medicine, Emory University School of Medicine, 143 Whitehead Research Building, 615 Michael St., Atlanta, GA 30322. E-mail: msherma@emory.edu. 
generated for later cycles of degranulation from the same mast cell, demonstrating the potency of these cells and their potential for serious effects on surrounding tissue. ${ }^{10}$

Mast cell granules contain a variety of bioactive proteins that cause inflammation. The neutrophil chemoattractants leukotriene $B_{4}$, interleukin 8 (kerotinocyte-derived chemokine in rodents), macrophage inflammatory protein-2, and tumor necrosis factor- $\alpha$ (TNF- $\alpha$ ) are all prestored in mast cells and can be released within seconds of cell activation (see review ${ }^{11}$ ). In addition, histamine and serotonin will induce vascular permeability, which allows influx of fluid, immune cells, and proteins to the damaged tissue. ${ }^{12}$ A placebo-controlled, doubleblind study using human volunteers that were orally challenged with $75 \mathrm{mg}$ of pure histamine demonstrated that histamine induces gastrointestinal symptoms within 3 to 24 hours after ingestion. ${ }^{13}$ Interestingly, common foods such as cheese, tuna, and tomatoes can contain up to $500 \mathrm{mg} / \mathrm{kg}$ histamine and may contribute to the development of food sensitivities.

In a rat model using cholera toxin to induce secretory diarrhea, the intestinal fluid released after toxin injection contains the cytokines interleukin $1 \beta$ and TNF- $\alpha .{ }^{14}$ These cytokines are made in large quantities by mast cells; in fact, the majority of TNF- $\alpha$-producing cells in intestinal lamina propria are mast cells. ${ }^{15}$ The release of cytokines into the intestinal lumen can induce the inflammatory cascade resulting in colitis.

\section{How Do Mast Cells Detect Bacteria?}

Studies performed in the 1970s demonstrated that mast cells can interact directly with pathogens through complement receptor 3 and FcgR after opsonization. ${ }^{10}$ Other studies by Malaviya et $\mathrm{al}^{16}$ demonstrated that mast cells recognize the fimbrial lectin FimH on $E$. coli through CD48. The direct binding of bacteria by mast cells leads to phagocytosis and killing of the bacteria, demonstrating that mast cells can act as a first line of defense against bacterial infections (see review ${ }^{10}$ ).

Mast cells also express TLRs and can react to microbial products, as shown here by Feng et al. ${ }^{1}$ TLRs comprise a family of cell-surface receptors that bind to various microbial molecular patterns and stimulate proinflammatory cytokine production (see review ${ }^{17}$ ). Human mast cells derived from cord blood were demonstrated to engulf and destroy a variety of bacterial strains while secreting considerable amounts of TNF- $\alpha .{ }^{18}$ Mast cells express TLR2, TLR4, TLR6, and TLR8, ${ }^{19,20}$ allowing detection of peptidoglycan from gram-positive bacteria and lipopolysaccharide from gram-negative bacteria among other bacterial products.

Mast cell-deficient mice are acutely sensitive to peritonitis because of a lack of neutrophil recruitment by mast cell TNF- $\alpha .{ }^{21}$ Reconstitution of mast cell-deficient mice with wild-type mast cells rescues the mice and allows clearance of the bacteria, but reconstitution with TLR4defective mast cells correlates with poor neutrophil recruitment and higher mortality. ${ }^{19}$ These studies demon- strate that TLR signaling in mast cells is crucial for innate immune protection from bacterial infection.

Interestingly, Supajatura et $\mathrm{al}^{22}$ demonstrated that TLR2 and TLR4 signaling in murine mast cells show quantitative and qualitative differences in cytokine production. Importantly, TLR2- but not TLR4-dependent mast cell activation results in degranulation. Moreover, intradermal injection of peptidoglycan induces vasodilation and inflammation of the skin via TLR2 signaling in mast cells. ${ }^{22}$ These previous observations support the work of Yang et al, ${ }^{1}$ demonstrating that peptidoglycan activation of mast cells in the intestinal tract can also cause inflammation and vasodilation.

\section{Are Mast Cells a Target for Therapy?}

Ketotifen, a potent mast cell stabilizer, has been used to control asthma allergy but has also been shown to effectively protect against enteritis. In a rat model of clostridium toxin disease, ketotifen prevents intestinal damage. ${ }^{23}$ Ketotifen is also effective against cholera toxin in a rat ileum model. ${ }^{14}$ Importantly, ketotifen leads to improvement or remission in human patients suffering from inflammatory bowel disease. ${ }^{24,25}$ The Feng et al study ${ }^{1}$ presented in this issue of the AJP broadens the effects of ketotifen to gram-positive bacterial infection in mice. Moreover, a combination of histamine $\mathrm{H} 1$ antagonist and 5-hydroxytryptamine 3 antagonist also blocked peptidoglycan-induced diarrhea. Together, these studies suggest that mast cells contribute to intestinal disease because of their sensitivity to bacterial products and ability to release potent inflammatory mediators, suggesting a potential therapeutic target for bacterial enteritis in combination with antibiotics.

\section{References}

1. Feng BS, He SH, Zheng PY, Wu L, Yang PC: Mast cells play a crucial role in Staphylococcus aureus peptidoglycan-induced diarrhea. Am J Pathol 2007, 171:537-547

2. Hiatt R, Katz L: Mast cells in inflammatory conditions of the gastrointestinal tract. Am J Gastroenterol 1962, 37:541-545

3. King T, Biddle W, Bhatia P, Moore J, Miner Jr PB: Colonic mucosal mast cell distribution at line of demarcation of active ulcerative colitis. Dig Dis Sci 1992, 37:490-495

4. Gelbmann CM, Mestermann S, Gross V, Kollinger M, Scholmerich J, Falk W: Strictures in Crohn's disease are characterised by an accumulation of mast cells colocalised with laminin but not with fibronectin or vitronectin. Gut 1999, 45:210-217

5. Shanahan F, Duerr R, Rotter J, Yang H, Sutherland L, McElree C, Landers C, Targan S: Neutrophil autoantibodies in ulcerative colitis: familial aggregation and genetic heterogeneity. Gastroenterology 1992, 103:456-461

6. Gordon LK, Eggena M, Targan SR, Braun J: Mast cell and neuroendocrine cytoplasmic autoantigen(s) detected by monoclonal pANCA antibodies. Clin Immunol 2000, 94:42-50

7. Araki Y, Andoh A, Fujiyama Y, Bamba T: Development of dextran sulphate sodium-induced experimental colitis is suppressed in genetically mast cell-deficient Ws/Ws rats. Clin Exp Immunol 2000 119:264-269

8. Wershil BK, Castagliuolo I, Pothoulakis C: Direct evidence of mast cell involvement in Clostridium difficile toxin A-induced enteritis in mice. Gastroenterology 1998, 114:956-964

9. Brandt EB, Strait RT, Hershko D, Wang Q, Muntel EE, Scribner TA, 
Zimmermann N, Finkelman FD, Rothenberg ME: Mast cells are required for experimental oral allergen-induced diarrhea. J Clin Invest 2003, 112:1666-1677

10. McLachlan JB, Abraham SN: Studies of the multifaceted mast cell response to bacteria. Curr Opin Microbiol 2001, 4:260-266

11. Malaviya R, Abraham SN: Clinical implications of mast cell-bacteria interaction. J Mol Med 1998, 76:617-623

12. Majno G, Palade G: The effect of histamine and serotonin on vascular permeability: an electron microscopic study. J Biophys Biochem Cytol 1961, 11:571-605

13. Wöhrl S, Hemmer W, Focke M, Rappersberger K, Jarisch R: Histamine intolerance-like symptoms in healthy volunteers after oral provocation with liquid histamine. Allergy Asthma Proc 2004, 25:305-311

14. Rocha MF, Aguiar JE, Sidrim JJ, Costa RB, Feitosa RF, Ribeiro RA, Lima AA: Role of mast cells and pro-inflammatory mediators on the intestinal secretion induced by cholera toxin. Toxicon 2003, 42:183-189

15. Bischoff SC, Lorentz A, Schwengberg S, Weier G, Raab R, Manns MP: Mast cells are an important cellular source of tumour necrosis factor $\alpha$ in human intestinal tissue. Gut 1999, 44:643-652

16. Malaviya R, Gao Z, Thankavel K, van der Merwe PA, Abraham SN: The mast cell tumor necrosis factor alpha response to FimH-expressing Escherichia coli is mediated by the glycosylphosphatidylinositolanchored molecule CD48. Proc Natl Acad Sci USA 1999, 96: $8110-8115$

17. Trinchieri G, Sher A: Cooperation of Toll-like receptor signals in innate immune defence. Nat Rev Immunol 2007, 7:179-190
18. Arock M, Ross E, Lai-Kuen R, Averlant G, Gao Z, Abraham SN: Phagocytic and tumor necrosis factor $\alpha$ response of human mast cells following exposure to gram-negative and gram-positive bacteria. Infect Immun 1998, 66:6030-6034

19. Supajatura V, Ushio H, Nakao A, Okumura K, Ra C, Ogawa H: Protective roles of mast cells against enterobacterial infection are mediated by toll-like receptor 4. J Immunol 2001, 167: 2250-2256

20. McCurdy JD, Lin TJ, Marshall JS: Toll-like receptor 4-mediated activation of murine mast cells. J Leukoc Biol 2001, 70:977-984

21. Malaviya R, Ikeda T, Ross E, Abraham SN: Mast cell modulation of neutrophil influx and bacterial clearance at sites of infection through TNF- $\alpha$. Nature 1996, 381:77-80

22. Supajatura V, Ushio H, Nakao A, Akira S, Okumura K, Ra C, Ogawa $\mathrm{H}$ : Differential responses of mast cell Toll-like receptors 2 and 4 in allergy and innate immunity. J Clin Invest 2002, 109:1351-1359

23. Pothoulakis C, Karmeli F, Kelly CP, Eliakim R, Joshi MA, O'Keane CJ, Castagliuolo I, LaMont JT, Rachmilewitz D: Ketotifen inhibits Clostridium difficile toxin A-induced enteritis in rat ileum. Gastroenterology 1993, 105:701-707

24. Marshall JK, Irvine EJ: Ketotifen treatment of active colitis in patients with 5-aminosalicylate intolerance. Can J Gastroenterol 1998, 12:273-275

25. Jones NL, Roifman CM, Griffiths AM, Sherman P: Ketotifen therapy for acute ulcerative colitis in children: a pilot study. Dig Dis Sci 1998, 43:609-615 